\title{
Transplant strategies for type 1 diabetes: whole pancreas, islet and porcine beta cell therapies
}

\author{
Melena D. Bellin ${ }^{1,2}$ (D) Ty B. Dunn ${ }^{3}$ (D) \\ Received: 9 March 2020 / Accepted: 14 April 2020 / Published online: 31 August 2020 \\ (C) Springer-Verlag GmbH Germany, part of Springer Nature 2020
}

\begin{abstract}
Whole-organ pancreas and islet transplantations are performed in a highly selected group of patients with diabetes mellitus, primarily those with type 1 diabetes mellitus, complicated by recurrent severe hypoglycaemia or renal failure requiring kidney transplantation. Clinical accessibility to pancreases or islets, and patient characteristics and therapeutic goals, may dictate choice of procedure. Pancreas transplantation is most often performed simultaneous with a kidney transplant, but patients with particularly labile type 1 diabetes may be considered for a pancreas transplant alone. While highly successful at restoring insulin independence, pancreas transplants carry the significant risks of major surgery and immunosuppression. Islet transplantation is a relatively minor procedure, usually performed for labile type 1 diabetes with severe hypoglycaemia. It is highly successful at resolving hypoglycaemia, but more than one pancreas donor may be required for insulin independence. Both pancreas and islet transplantation are limited in applicability by a paucity of deceased donors. Pigs provide one promising replenishable source of islets. Porcine islets can successfully reverse diabetes mellitus in non-human primates under the appropriate immunosuppressive conditions, with promise for eventually translating this success to a larger population of patients with diabetes mellitus in the future.
\end{abstract}

Keywords Diabetes $\cdot$ Hypoglycaemia $\cdot$ Immunosuppression $\cdot$ Islet $\cdot$ Kidney $\cdot$ Pancreas $\cdot$ Transplant $\cdot$ Type 1 diabetes

$\begin{array}{ll}\text { Abbreviations } \\ \text { CFRD } & \text { Cystic fibrosis-related diabetes } \\ \text { CIT } & \text { Clinical Islet Transplant } \\ \text { CNI } & \text { Calcineurin inhibitor } \\ \text { IBMIR } & \text { Instant blood-mediated inflammatory response } \\ \text { ITA } & \text { Islet transplant alone } \\ \text { PAK } & \text { Pancreas-after-kidney } \\ \text { PERV } & \text { Porcine endogenous retrovirus }\end{array}$

Electronic supplementary material The online version of this article (https://doi.org/10.1007/s00125-020-05184-7) contains a slide of the figure for download, which is available to authorised users.

Melena D. Bellin

bel10130@umn.edu

1 Medical School, University of Minnesota, Minneapolis, MN, USA

2 Department of Pediatrics, University of Minnesota Masonic Children's Hospital, East Building Rm MB 671, 2450 Riverside Ave S, Minneapolis, MN 55454, USA

3 Department of Surgery, Division of Transplantation, Perelman School of Medicine, University of Pennsylvania, Pennsylvania, PA, USA $\begin{array}{ll}\text { PTA } & \text { Pancreas transplant alone } \\ \text { SPK } & \text { Simultaneous pancreas-kidney }\end{array}$

\section{Introduction}

Despite advancements in insulin analogues, continuous glucose monitors and closed-loop insulin pump technology, treatment of type 1 diabetes mellitus with exogenous insulin remains complicated by hyperglycaemia and hypoglycaemia. For selected patients with diabetes mellitus who require kidney transplant or who experience recurrent severe hypoglycaemia despite optimal medical therapy, wholeorgan pancreas or isolated islet transplantation can restore normal glucose homeostasis $[1,2]$. However, application of these transplant therapies is limited to a small number of patients with diabetes mellitus due to the limited number of deceased pancreas donors and the need for immunosuppression therapy to prevent alloimmune rejection and recurrent beta cell autoimmunity. Currently, the majority of patients with diabetes mellitus who undergo pancreas or islet transplantation have type 1 diabetes mellitus that is complicated 
by either renal failure or recurrent severe hypoglycaemia $[2$, 3]. Less often, pancreas transplants are performed for other forms of diabetes mellitus, including type 2 diabetes mellitus, cystic fibrosis-related diabetes mellitus (CFRD) and postpancreatectomy diabetes mellitus $[4,5]$. Research is ongoing to develop replenishable sources of islets, including stem cellderived islets and porcine islets, to allow expansion of transplant options to a larger group of patients with diabetes mellitus.

In this review, we will summarise recent advances and clinical applications of transplant therapies for diabetes mellitus, including pancreas transplants, cadaveric-donor islet transplants and xenoislet transplants (see Text box).

\section{Determining candidacy for pancreas or islet transplants in type 1 diabetes}

Pancreas or islet transplantation may be considered for patients with type 1 diabetes who require kidney transplantation or who have 'brittle' forms of type 1 diabetes characterised by labile glycaemic control and recurrent severe hypoglycaemia despite optimal medical therapy [6]. While protocols differ by institution, 'brittle' (labile) type 1 diabetes is often defined by $\geq 1$ episode of severe hypoglycaemia per year, with hypoglycaemic unawareness, as assessed by a standardised instrument, such as the Clarke scale [2]. Whether a whole-organ pancreas or pancreatic islets are transplanted depends, in part, on clinical accessibility to these procedures. In the USA, whole-organ pancreas transplants can be accessed as a clinical procedure, whereas isolated islets can only be administered under an 'investigational new drug' protocol [7]. In contrast, in some provinces of Canada and in many European countries, both whole-organ pancreas and islets are accessible as clinical therapies [8]. Allocation of pancreases for whole-organ or islet transplantation also varies and may have an impact on accessibility. Although in the UK pancreases and islets are on a shared allocation list, in many areas of the world, islets are isolated from pancreases that are declined for whole-organ transplantation [9].

\begin{tabular}{|c|c|c|c|c|}
\hline $\begin{array}{l}\text { Transplantation } \\
\text { approach }\end{array}$ & $\begin{array}{c}\text { Clinical } \\
\text { accessibility }\end{array}$ & Advantages & Disadvantages & Therapeutic goals \\
\hline \multirow[t]{2}{*}{$\begin{array}{l}\text { Pancreas } \\
\text { transplantation }\end{array}$} & \multirow[t]{2}{*}{ Clinical procedure } & \multirow{2}{*}{$\begin{array}{l}\text { High potential for } \\
\text { insulin } \\
\text { independence with } \\
\text { single transplant }\end{array}$} & $\begin{array}{l}\text { Major surgical } \\
\text { procedure; } \\
\text { increased risk of } \\
\text { surgical morbidity }\end{array}$ & $\begin{array}{l}\text { Insulin } \\
\text { independence } \\
\text { (primary) }\end{array}$ \\
\hline & & & $\begin{array}{l}\text { surgical morbidity } \\
\text { Limited supply }\end{array}$ & $\begin{array}{l}\text { Eliminate } \\
\text { hypoglycaemia } \\
\text { (primary or } \\
\text { secondary) }\end{array}$ \\
\hline \multirow{4}{*}{$\begin{array}{l}\text { Human islet } \\
\text { transplantation }\end{array}$} & \multirow{4}{*}{$\begin{array}{l}\text { Research (USA); } \\
\text { clinical (selected } \\
\text { regions in Canada, } \\
\text { Europe and } \\
\text { elsewhere) }\end{array}$} & \multirow{4}{*}{$\begin{array}{l}\text { Minor procedure } \\
\text { Potential for } \\
\text { encapsulation }\end{array}$} & Delayed onset of & \multirow{2}{*}{$\begin{array}{l}\text { Eliminate } \\
\text { hypoglycaemia } \\
\text { (primary) }\end{array}$} \\
\hline & & & \multirow{2}{*}{$\begin{array}{l}\text { function } \\
>1 \text { transplant may } \\
\text { be needed for } \\
\text { insulin } \\
\text { independence }\end{array}$} & \\
\hline & & & & $\begin{array}{l}\text { Insulin } \\
\text { independence } \\
\text { (secondary) }\end{array}$ \\
\hline & & & Limited supply & \\
\hline \multirow[t]{3}{*}{ Porcine islets } & \multirow{3}{*}{$\begin{array}{l}\text { Research in non- } \\
\text { human primates; } \\
\text { more data needed } \\
\text { for human studies }\end{array}$} & $\begin{array}{l}\text { Unlimited islet } \\
\text { supply }\end{array}$ & \multirow{3}{*}{$\begin{array}{l}\text { More challenging } \\
\text { to immunoprotect } \\
\text { xenoislets } \\
\text { Increased safety } \\
\text { concerns (xenotic } \\
\text { infection, PERV) }\end{array}$} & \multirow[t]{3}{*}{ To be determined } \\
\hline & & $\begin{array}{l}\text { Potential for } \\
\text { genetic } \\
\text { engineering }\end{array}$ & & \\
\hline & & $\begin{array}{l}\text { Potential for } \\
\text { encapsulation }\end{array}$ & & \\
\hline
\end{tabular}


When either therapy is an option, patient characteristics and patient goals dictate selection of the procedure [6]. Islet transplant carries a lower risk for surgical morbidity and complications and is highly successful at eliminating severe hypoglycaemia and glucose lability. However, more than one pancreas donor may be needed to achieve insulin independence. In contrast, pancreas transplantation carries higher surgical morbidity and risks, but has a high likelihood of resulting in insulin independence after a single transplant. Patients with high insulin needs and high BMI are often not candidates for islet transplantation due to the inability of an isolated islet graft to meet the insulin demand in these individuals; however, they may be candidates for a whole-organ pancreas transplantation. In contrast, patients who are poor candidates for major surgery, including those with cardiopulmonary disease or old-aged individuals, may better tolerate the minor procedure of islet infusion.

\section{Pancreas transplantation}

The first successful pancreas transplant was performed in a recipient with type 1 diabetes in 1966 [10]. As of 2014, more than 48,000 pancreas transplants had been performed worldwide [1]. Pancreas transplants can be performed as simultaneous pancreas-kidney (SPK) transplants, pancreas-afterkidney (PAK) transplants or as pancreas transplant alone (PTA). SPK transplants are most commonly performed, comprising about $80 \%$ of contemporary pancreas transplants, as this procedure can ameliorate diabetes mellitus in a patient who already requires major surgery and immunosuppression for renal transplant [5]. While most patients undergoing pancreas transplantation have type 1 diabetes, SPK transplants are increasingly being performed for those with type 2 diabetes, with $14 \%$ of all pancreas transplant recipients now carrying a primary diagnosis of type 2 diabetes in the USA [5]. Rarely, pancreas transplants are performed for less common forms of diabetes mellitus, including post-pancreatectomy diabetes mellitus, in which pancreas transplantation can reverse both endocrine and exocrine insufficiency [11, 12], and in CFRD, in which pancreas transplantation has been combined with liver or lung transplantation [4].

Recent data from over 20,000 pancreas transplants performed in the USA suggest that the proportion of recipients who are insulin independent 5 years after pancreas transplantation is $73 \%$ for SPK transplantation, $64 \%$ for PAK transplantation and 53\% for PTA, and the proportion who are insulin independent 10 years post transplantation is $56 \%, 38 \%$ and $36 \%$, respectively [13]. Pancreas graft survival is superior at high-volume centres in the USA and Europe, despite these centres accepting higher risk organs for transplant. Highvolume centres were defined as those performing $>11-14$ procedures per year (depending on the type of transplant and on definitions used in US and European analyses) [14-16]. While surgical techniques for pancreas transplantation (Fig. 1) have evolved over time, with a focus on the mitigation of complications related to thrombosis or the exocrine pancreas, refinements in graft selection and immunosuppression have been the hallmark of recent improvements. Conventional immunosuppression for pancreas transplantation consists of induction therapy with a $\mathrm{T}$ cell-depleting agent (antithymocyte globulin or alemtuzumab) and two-drug maintenance therapy, typically with a calcineurin inhibitor $(\mathrm{CNI}$; tacrolimus) and mycophenolate mofetil. Although risk for CNI nephrotoxicity remains a concern, there are cases reported of successful substitution of tacrolimus with belatacept, a selective blocker of $\mathrm{T}$ cell costimulation that does not exhibit renal toxicity, in the setting of CNI-induced renal insufficiency [17].

Recent innovations have focused on expanding the pancreas donor pool and reducing geographical disparities in access to pancreas transplants. Historically, pancreases for transplant have been procured only from donors after brain death, while organs from donors after cardiac death were considered unsuitable due to concerns for suboptimal graft function. However, emerging evidence suggests that 1 year graft survival rates after pancreas transplantation with or without simultaneous kidney transplant are similar with organs from circulatory death vs brain death donors, thus expanding the potential pool of organs available for transplantation [18]. In 2014, a new pancreas allocation system was implemented in the USA, with the goal of improving access to pancreas transplants and increasing organ utilisation. Subsequent refinements in organ allocation policies increased, then eliminated the maximum allowable recipient BMI, and removed C-peptide criteria for type 2 diabetes. Subsequent analyses suggest that these changes in organ allocation have decreased wait time and have reduced, but not eliminated, geographical variation in SPK transplants [3].

\section{Human islet transplantation}

Between 1999 and 2015, over 1000 patients with type 1 diabetes received one or more islet infusions, with the majority being islet transplant alone (ITA; 81\%), with islet-afterkidney (IAK) transplantation occurring less often (17\%) and simultaneous islet-kidney transplantation being rare [19]. Compared with whole-organ pancreas transplantation, islet cell-transplant therapies carry greater opportunity for innovation, including the potential for renewable cell sources (see below), and for engineering strategies that reduce immunogenicity and reduce or eliminate the need for immunosuppression. Thus, much excitement has revolved around cell therapy as the future of type 1 diabetes management. 
Fig. 1 Procedure and postoperative anatomy for wholeorgan pancreas transplantation with enteric drainage (a) and alloislet transplantation (b). In (a), the pancreas is anastomosed to the recipient's small intestine for drainage of the exocrine pancreas. In (b), islets are isolated from donor pancreases by collagenase digestion. Islets are purified to remove exocrine fragments and purified islets (containing beta, alpha and delta cells) are transplanted into the hepatic portal vein. Subsequently, islets engraft into the liver of the recipient. The figure in (b) is from [45]. Copyright 2004

Massachusetts Medical Society. Reprinted with permission from Massachusetts Medical Society. This figure is available as a downloadable slide a
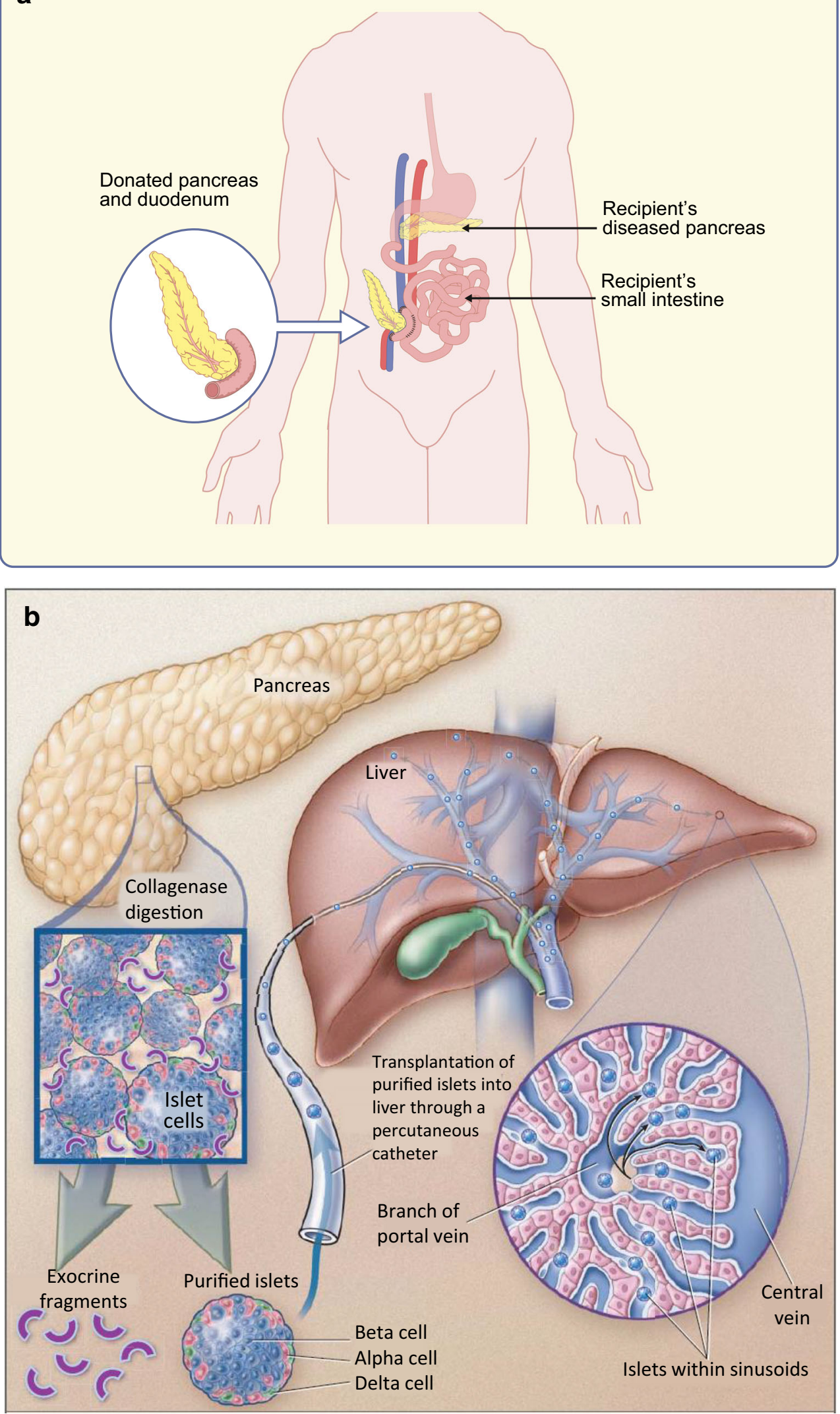
Since islet transplants have often been performed under research protocols with varying immunoprotective strategies, overall outcomes are variable, depending on the treatment protocol and patient selection. The large multicentre Clinical Islet Transplant (CIT) trial in the USA is the main licensuresupporting trial for islets, enrolling adults with long-standing type 1 diabetes complicated by hypoglycaemia unawareness and recurrent severe hypoglycaemia. In the CIT trial, $87 \%$ achieved the primary endpoint, which was complete resolution of severe hypoglycaemia with $\mathrm{HbA}_{1 \mathrm{c}}<53 \mathrm{mmol} / \mathrm{mol}(<7 \%)$ at 1 year, while $52 \%$ were insulin independent [2]. In addition, hypoglycaemia fear and diabetes distress were significantly reduced [20]. Studies designed to provide head-to-head comparisons of islet transplantation with best medical practices for type 1 diabetes suggest that islets are superior to medical therapy in resolving severe hypoglycaemia while maintaining tight glycaemic control. In patients with early microvascular complications, islet transplantation is superior in preventing the progression of these complications [21-23]. However, patients must be carefully selected, as these benefits are counter-balanced by risks of long-term immunosuppression.

Currently, the mainstay of cellular therapy is to transplant human islets isolated from brain-dead cadaveric donors. The surgical procedure for islet infusion is relatively minor and can be performed either via a minilaparotomy to access and cannulate an omental vessel, or by transhepatic percutaneous infusion into the portal vein under radiological guidance (Fig. 1b). In either case, the islets are infused into the portal vasculature and engraft in the liver. While glucose stability is imparted within days to weeks, insulin independence (if it is achieved) is delayed for several months, as the isolated islets must engraft and revascularise in the new liver environment before reaching full functionality [2].

Although the intraportal site is appealing due to its ease of access and success of this approach in large animal models, infusion of the islets directly into the vasculature elicits a proinflammatory and procoagulatory instant blood-mediated inflammatory response (IBMIR), which induces islet damage and islet loss [24]. Thus, one area of ongoing research is the utility of alternate sites for islet allotransplant. Alloislet transplantation into bone marrow was unsuccessful in one small trial, while a biological scaffold created by layering islets with thrombin in an omental pouch has shown some early success, but was not superior to transplanting islets into the liver site [25]. One appeal of creating a biological omental scaffold is that this type of implantation site could allow future transplant-site engineering, including adding trophic factors or local immunoprotection strategies to the scaffold environment [26].

To be successful, human cadaveric-donor islet transplants require immunosuppression. When $\mathrm{T}$ cell-depleting medications are administered with TNF- $\alpha$ inhibition for induction of immunosuppression, insulin independence at 5 years post ITA is similar to that observed in those who underwent PTA $(\sim 50 \%)$, though more than one islet infusion may be required to achieve insulin independence [27]. As with pancreas transplantation, two-drug maintenance immunosuppression is needed to maintain a functioning islet graft, with CNI therapy (tacrolimus or ciclosporin) usually being a critical component of this maintenance regimen [28]. However, costimulation blockade may represent an alternative CNI-sparing approach; long-term insulin independence and islet function has been demonstrated in small cohorts of patients treated with the costimulatory blockers efalizumab or belatacept. These regimens hold appeal due to the lack of potential for renal toxicity [29].

An alternative strategy to systemic immunosuppression is to encapsulate islets so that they are locally immunoprotected and, hence, there is no need for potent immunosuppressive drugs. One small trial of human islets that were transplanted subcutaneously in a macroencapsulated device with intradevice oxygen delivery suggested that islets were able to survive within the device, and low levels of circulating Cpeptide were detected early after transplantation. However, these devices were not sufficient to maintain long-term islet viability and no long-term glycaemic benefit was observed [30]. Research is ongoing into strategies to limit immunosuppression exposure, including macro- or microencapsulation and short-term treatment to induce tolerance. One recent non-human primate study of alloislet transplantation suggested that the administration of apoptotic donor splenocytes with short-term immunosuppression $(\sim 2$ weeks) induced antigen-specific self tolerance and rejection-free islet survival for 1 year post transplantation [31].

Complicating head-to-head comparisons of pancreas vs islet transplantation is a lack of uniform definitions for success in beta cell replacement therapy. While there has been an effort to standardise a global definition for graft success via creation of the Igls criteria (which incorporates glycaemic measures, insulin use and C-peptide production), this has not yet been widely implemented [32].

\section{Novel non-stem-cell sources of islets}

In the USA alone, there are 1.25 million individuals with type 1 diabetes. The number of deceased donors of pancreases or islets is only sufficient to treat a small fraction of this population. Ultimately, in order for beta cell replacement therapy to truly provide a 'cure', new and renewable sources of islets (or beta cells) are needed. Current work has focused on two potential future sources for islets: (1) stem cell-derived islets (which are not a focus of the current review); and (2) xenogeneic islets isolated from neonatal or adult pigs. Porcine islets are appealing because porcine tissues are already used safely in other areas of clinical practice, porcine insulin is effective in 
humans and the porcine beta cell has a 'set point' for glucose similar to human islets. New technologies in genetic engineering also present an opportunity to genetically modify porcine islet source pigs to be less immunogenic [33].

To date, trials of porcine islet xenografts transplanted into non-human primate models have established a potential to achieve insulin independence and prolonged islet-graft function ( $>600$ days) $[34,35]$. Xenoislet transplantation presents a greater immunological hurdle compared with islet allotransplantation. Intraportal infusion of porcine islets (adult or neonatal) can trigger an early immunological response to pig-specific antigens expressed by the islet, most notably galactose-alpha-1,3-galactose (Gal epitope) [36]. This can further exacerbate IBMIR when islets are infused intraportally. Use of genetically engineered galactose-alpha-1,3-galactose-deficient pigs may reduce the risk for hyperacute rejection and improve islet-graft survival rate [36]. Use of alternate sites for transplantation is another approach to avoid IBMIR [36]. The ideal transplant site for porcine islets remains unclear; however, in selecting a transplant site, one must balance the desire to avoid IBMIR (the greatest risk being in the intraportal site) with the need for access to adequate oxygenation and the potential for revascularisation [37].

Immunosuppression or immunoprotection is required to prevent early and late ( $\mathrm{T}$ cell-mediated) islet loss. One strategy to prevent immunorejection is to transplant porcine islets using microencapsulation or macroencapsulation in the absence of immunosuppression [38]. To succeed, this approach must allow encapsulated islets sufficient oxygen delivery to be viable and sufficient diffusion properties to allow normal glucose-stimulated insulin secretion. Alternatively, xenoislets can be transplanted under the cover of immunosuppression, likely with costimulatory blockade as part of the immunosuppressive approach. Non-human primate studies have shown prolonged islet-graft survival when porcine islets were infused intraportally under a regimen that included costimulatory blockade with an anti-CD154 monoclonal antibody alongside additional standard immunosuppressive agents [35, 39]. However, an anti-CD154 monoclonal antibody is not currently clinically available due to a high risk of thrombosis associated with its use [39].

The ideal porcine donor for human transplant needs to be defined. Considerations include the age of the porcine donor (adult, juvenile, neonatal), porcine breed, and potential for genetic modifications to increase islet survival or improve functionality. Both neonatal and adult porcine islets have successfully reversed diabetes in non-human primates [34-36, 40]. The advantages of neonatal islets include lower cost, relative resistance to hypoxia and technically easier isolation, while advantages of adult porcine islets include a higher islet mass per pancreas and islets that are fully matured and functional at the time of isolation [37]. Different breeds of pigs may yield different islet masses and islet functionality. Limited data comparing adult porcine (Landrace pig) with human islets have suggested lower insulin secretion, both in vitro and in vivo, with porcine islets; the dynamics of porcine-islet insulin-secretory capacity (vs human islets) may warrant consideration when optimising islet dose for xenoislet transplantation for clinical recipients in the future [41].

Specific to porcine-islet transplantation is the concern of transmission of xenotic infections. In particular, porcine endogenous retroviruses (PERVs) are ubiquitous across pig breeds. A very small number of patients with type 1 diabetes have received islet xenografts from neonatal pigs, which were transplanted into a subcutaneous collagen-covered device or microencapsulated in alginate. Despite unclear clinical benefit, reassuringly, no transmission of PERVs or other xenotic infection was observed [38, 42]. However, PERV transmission from porcine to human cells has been observed in vitro. Genetically engineered pigs with PERV inactivation using CRISPR-Cas9 technology have recently emerged as a potential strategy to mitigate this risk [43]. Monitoring for PERV infection will be an important safety consideration as more porcine-islet products enter human testing [44].

The International Xenotransplantation Association has developed consensus guidelines for undertaking clinical trials [44]. These guidelines highlight important considerations for the risk:benefit ratio of moving forward with clinical trials in xenoislet transplantation, and for the long-term safety of recipients. These guidelines recommend robust supportive data in non-human primates, defined by near normoglycaemia with a substantial reduction in insulin need and demonstration of glucose- or arginine-stimulated insulin (C-peptide) production, before clinical studies are conducted. Pigs used as an islet source need to be housed in a closed, pathogen-free setting with well-defined monitoring protocols for designated pathogens, including PERVs. Long-term monitoring of recipients for PERV transmission and the transmission of other infections must also be carried out.

\section{Conclusions}

Both pancreas and human islet transplantation can provide substantial benefits for patients with type 1 diabetes complicated by recurrent severe hypoglycaemia or renal failure. Selection of the optimal therapeutic modality is influenced by clinical accessibility, patient characteristics and the goals of transplantation (e.g. to eliminate hypoglycaemia with less risk of morbidity with islets, or early attainment of insulin independence with pancreas transplantation at the expense of a higher risk surgery). Regardless, both pancreas and human islet transplantation are limited by the small number of appropriate cadaveric pancreas donors. Xenogeneic porcine islets hold potential for offering transplantation to a larger population of patients with type 1 diabetes in the future. 
Authors' relationships and activities MDB discloses the following conflicts of interest: research support from Viacyte and Dexcom; Data Safety Monitoring Board membership for Insulet. TBD declare that there are no relationships or activities that might bias, or be perceived to bias, their work

Contribution statement $\mathrm{MDB}$ and TBD were responsible for drafting the article and revising it critically for important intellectual content. Both authors approved the version to be published.

\section{References}

1. Gruessner AC, Gruessner RW (2016) Pancreas transplantation of US and non-US cases from 2005 to 2014 as reported to the United Network for Organ Sharing (UNOS) and the International Pancreas Transplant Registry (IPTR). Rev Diabet Stud 13(1):35-58

2. Hering BJ, Clarke WR, Bridges ND et al (2016) Phase 3 trial of transplantation of human islets in type 1 diabetes complicated by severe hypoglycemia. Diabetes Care 39(7):1230-1240

3. Concepcion BP, Feurer ID, Rega SA, Niederhaus S, Odorico J, Forbes RC (2020) Geographic disparities in access to simultaneous pancreas and kidney transplant in the pre- and post-pancreas allocation system eras. Transplantation 104(3):623-631

4. Usatin DJ, Perito ER, Posselt AM, Rosenthal P (2016) Under utilization of pancreas transplants in cystic fibrosis recipients in the United Network Organ Sharing (UNOS) data 1987-2014. Am J Transplant 16(5):1620-1625

5. Kandaswamy R, Stock PG, Gustafson SK et al (2020) OPTN/ SRTR 2018 annual data report: pancreas. Am J Transplant 20(Suppl s1):131-192

6. Wojtusciszyn A, Branchereau J, Esposito L et al (2019) Indications for islet or pancreatic transplantation: statement of the TREPID working group on behalf of the Societe Francophone du Diabete (SFD), Societe Francaise d'Endocrinologie (SFE), Societe Francophone de Transplantation (SFT) and Societe Francaise de Nephrologie - Dialyse - Transplantation (SFNDT). Diabetes Metab 45(3):224-237

7. Pepper AR, Bruni A, Shapiro AMJ (2018) Clinical islet transplantation: is the future finally now? Curr Opin Organ Transplant 23(4): 428-439

8. Ling Y, Gill A, Oram R, Shapiro AMJ, Senior P (2018) Clinical islet transplantation for adults with type 1 diabetes in Canada: referral patterns and eligibility assessment. Can J Diabetes 42(4):419425

9. Hudson A, Bradbury L, Johnson R et al (2015) The UK pancreas allocation scheme for whole organ and islet transplantation. Am J Transplant 15(9):2443-2455

10. Kelly WD, Lillehei RC, Merkel FK, Idezuki Y, Goetz FC (1967) Allotransplantation of the pancreas and duodenum along with the kidney in diabetic nephropathy. Surgery 61(6):827-837

11. Gruessner RW, Sutherland DE, Drangstveit MB, Kandaswamy R, Gruessner AC (2008) Pancreas allotransplants in patients with a previous total pancreatectomy for chronic pancreatitis. J Am Coll Surg 206(3):458-465

12. Cerise A, Nagaraju S, Powelson JA, Lutz A, Fridell JA (2019) Pancreas transplantation following total pancreatectomy for chronic pancreatitis. Clin Transpl 33(12):e13731

13. Gruessner AC, Gruessner RW (2016) Long-term outcome after pancreas transplantation: a registry analysis. Curr Opin Organ Transplant 21(4):377-385

14. Kopp W, van Meel M, Putter H et al (2017) Center volume is associated with outcome after pancreas transplantation within the Eurotransplant region. Transplantation 101(6):1247-1253
15. Alhamad T, Malone AF, Brennan DC et al (2017) Transplant center volume and the risk of pancreas allograft failure. Transplantation 101(11):2757-2764

16. Kim Y, Dhar VK, Wima K et al (2017) The center volume-outcome effect in pancreas transplantation: a national analysis. J Surg Res 213:25-31

17. Mujtaba MA, Sharfuddin AA, Taber T et al (2014) Conversion from tacrolimus to belatacept to prevent the progression of chronic kidney disease in pancreas transplantation: case report of two patients. Am J Transplant 14(11):2657-2661

18. Muthusamy AS, Mumford L, Hudson A, Fuggle SV, Friend PJ (2012) Pancreas transplantation from donors after circulatory death from the United Kingdom. Am J Transplant 12(8):2150-2156

19. CITR Coordinating Center (2017) CITR tenth annual report. Available from: https://citregistry.org/system/files/10th_AR.pdf. Accessed $20 \mathrm{Feb} 2020$

20. Foster ED, Bridges ND, Feurer ID, Eggerman TL, Hunsicker LG, Alejandro R (2018) Improved health-related quality of life in a phase 3 islet transplantation trial in type 1 diabetes complicated by severe hypoglycemia. Diabetes Care 41(5):1001-1008

21. Lablanche S, Vantyghem MC, Kessler L et al (2018) Islet transplantation versus insulin therapy in patients with type 1 diabetes with severe hypoglycaemia or poorly controlled glycaemia after kidney transplantation (TRIMECO): a multicentre, randomised controlled trial. Lancet Diabetes Endocrinol 6(7):527-537

22. Thompson DM, Meloche M, Ao Z et al (2011) Reduced progression of diabetic microvascular complications with islet cell transplantation compared with intensive medical therapy. Transplantation 91(3):373-378

23. Fensom B, Harris C, Thompson SE, Al Mehthel M, Thompson DM (2016) Islet cell transplantation improves nerve conduction velocity in type 1 diabetes compared with intensive medical therapy over six years. Diabetes Res Clin Pract 122:101-105

24. Johansson H, Goto M, Dufrane D et al (2006) Low molecular weight dextran sulfate: a strong candidate drug to block IBMIR in clinical islet transplantation. Am J Transplant 6(2):305-312

25. Maffi $P$, Nano R, Monti $P$ et al (2019) Islet allotransplantation in the bone marrow of patients with type 1 diabetes: a pilot randomized trial. Transplantation 103(4):839-851

26. Baidal DA, Ricordi C, Berman DM et al (2017) Bioengineering of an intraabdominal endocrine pancreas. N Engl J Med 376(19): 1887-1889

27. Bellin MD, Barton FB, Heitman A et al (2012) Potent induction immunotherapy promotes long-term insulin independence after islet transplantation in type 1 diabetes. Am J Transplant 12(6): 1576-1583

28. Barton FB, Rickels MR, Alejandro R et al (2012) Improvement in outcomes of clinical islet transplantation: 1999-2010. Diabetes Care 35(7):1436-1445

29. Posselt AM, Szot GL, Frassetto LA et al (2010) Islet transplantation in type 1 diabetic patients using calcineurin inhibitor-free immunosuppressive protocols based on T-cell adhesion or costimulation blockade. Transplantation 90(12):1595-1601

30. Carlsson PO, Espes D, Sedigh A et al (2018) Transplantation of macroencapsulated human islets within the bioartificial pancreas betaAir to patients with type 1 diabetes mellitus. Am J Transplant 18(7):1735-1744

31. Singh A, Ramachandran S, Graham ML et al (2019) Long-term tolerance of islet allografts in nonhuman primates induced by apoptotic donor leukocytes. Nat Commun 10(1):3495

32. Rickels MR, Stock PG, de Koning EJP et al (2018) Defining outcomes for $\beta$-cell replacement therapy in the treatment of diabetes: a consensus report on the Igls criteria from the IPITA/EPITA Opinion Leaders Workshop. Transplantation 102(9):1479-1486

33. Hering BJ, Walawalkar N (2009) Pig-to-nonhuman primate islet xenotransplantation. Transpl Immunol 21(2):81-86 
34. Cardona K, Milas Z, Strobert E et al (2007) Engraftment of adult porcine islet xenografts in diabetic nonhuman primates through targeting of costimulation pathways. Am J Transplant 7(10): $2260-2268$

35. Hering BJ, Wijkstrom M, Graham ML et al (2006) Prolonged diabetes reversal after intraportal xenotransplantation of wild-type porcine islets in immunosuppressed nonhuman primates. Nat Med 12(3):301-303

36. Thompson P, Badell IR, Lowe M et al (2011) Islet xenotransplantation using gal-deficient neonatal donors improves engraftment and function. Am J Transplant 11(12):2593-2602

37. Mourad NI, Gianello PR (2017) Xenoislets: porcine pancreatic islets for the treatment of type I diabetes. Curr Opin Organ Transplant 22(6):529-534

38. Matsumoto S, Abalovich A, Wechsler C, Wynyard S, Elliott RB (2016) Clinical benefit of islet xenotransplantation for the treatment of type 1 diabetes. EBioMedicine 12:255-262

39. Bottino R, Knoll MF, Graeme-Wilson J et al (2017) Safe use of anti-CD154 monoclonal antibody in pig islet xenotransplantation in monkeys. Xenotransplantation 24(1):e12283

40. Cardona K, Korbutt GS, Milas Z et al (2006) Long-term survival of neonatal porcine islets in nonhuman primates by targeting costimulation pathways. Nat Med 12(3):304-306
41. Graham ML, Bellin MD, Papas KK, Hering BJ, Schuurman HJ (2011) Species incompatibilities in the pig-to-macaque islet xenotransplant model affect transplant outcome: a comparison with allotransplantation. Xenotransplantation 18(6):328-342

42. Valdes-Gonzalez R, Dorantes LM, Bracho-Blanchet E, RodriguezVentura A, White DJ (2010) No evidence of porcine endogenous retrovirus in patients with type 1 diabetes after long-term porcine islet xenotransplantation. J Med Virol 82(2):331-334

43. Niu D, Wei HJ, Lin L et al (2017) Inactivation of porcine endogenous retrovirus in pigs using CRISPR-Cas9. Science 357(6357): 1303-1307

44. Hering BJ, Cozzi E, Spizzo T et al (2016) First update of the International Xenotransplantation Association consensus statement on conditions for undertaking clinical trials of porcine islet products in type 1 diabetes - executive summary. Xenotransplantation 23(1):3-13

45. Robertson RP (2004) Islet transplantation as a treatment for diabetes - a work in progress. N Engl J Med 350(7):697-705

Publisher's note Springer Nature remains neutral with regard to jurisdictional claims in published maps and institutional affiliations. 